\title{
IL-25 Involved in Airway Inflammation of OVA-Induced Asthmatic Mice and the Inhibitory Effect of Glucocorticoid
}

Hong-Jia Li ${ }^{1}$, Fen Liu1 ${ }^{1}$, De-Gan Lu${ }^{1}$, Ying-Hua Song ${ }^{1}$, Chao Wang ${ }^{1}$, Jin-Xiang Wu², Ji-Ping Zhao ${ }^{2}$, Cai-Qing Zhang ${ }^{1 *}$ and Liang Dong ${ }^{2 *}$

${ }^{1}$ Department of Pulmonary Disease, Qianfoshan Hospital, Shandong University, China

${ }^{2}$ Department of Pulmonary Diseases, Qilu Hospital of Shandong University, China

\begin{abstract}
Objective: To study the expression of IL-25 in airway inflammation of OVA-induced asthmatic mice and the effects of glucocorticoid.

Methods: The asthmatic mice were induced by ovalbumin (OVA) sensitization and challenge. This model was confirmed by detecting airway responsiveness, serum levels of IgE and lung histopathology. We also detected the inflammatory cells by cell counting plate and cytokines by ELISA, respectively. We also detected the expression of IL-25 by quantitative real-time PCR and immunohistochemistry.

Results: Compared with the mice in control group, the asthmatic mice showed elevated airway responsiveness and high serum levels of IgE. We also detected more inflammatory cells and high level of inflammatory cytokines in mice of OVA group. The expression of IL-25 was also significantly increased in both mRNA and protein levels in OVA group. Furthermore, treating mice with glucocorticoid could inhibit inflammatory cells and cytokines infiltration and reduce IL-25 expression.

Conclusion: IL-25 level is increased in OVA-induced asthmatic airway inflammation and glucocorticoid is capable of inhibiting IL-25 expression as well as other Th2 cytokines, thus presents a promising strategy for the treatment of asthma.
\end{abstract}

Keywords: Bronchial asthma; Airway inflammation; Interleukin-25; Glucocorticoid

\section{Introduction}

Allergic asthma is an inflammatory airway disease which is characterized by eosinophils and mast cells infiltration, goblet cell hyperplasia and airway hyperreactivity (AHR) [1]. IL-25 (IL-17E) is a member of IL-17 family and plays a critical role in inflammation and autoimmunity [2]. Recent studies have established that high level of IL-25 was associated with airway inflammatory disease in humans and mice [3] and could activate DCs to prime naive CD4+ T cells to differentiate into proinflammatory Th2 cells. To evaluate the role of IL25 in asthma, we generated the asthmatic mice model using OVA and identified the expression of IL-25 and Th2-type inflammatory cytokines in BALF in this process. We found that the expression of IL-25 mRNA and protein was significantly elevated in epithelial cells of mice with asthmatic inflammation, whereas treated with glucocorticoid decreased the eosinophils infiltration and IL-4, IL-5, and IL-13 in BALF [4]. This finding showed that IL-25 activated eosinophils to produce a range of asthmatic mediators and might play a pivotal role in maintaining Th2 central memory and sustaining asthmatic inflammation while glucocorticoid treatment was capable of inhibiting the procession.

\section{Materials and Methods}

\section{Animals}

Female BALB/c mice ( $n=30$, weight $25 \pm 5 \mathrm{~g}$ ) were obtained from the Animal Centre of Shandong University, P. R. China. The mice were randomly divided into three groups-asthma group $(\mathrm{n}=10)$, control group $(n=10)$ and glucocorticoid (GC)-treated group $(n=10)$. All animal experiments undertaken in this study were done so with the approval of the Institutional Animal Care and Use Committee [5] of Shandong University.

\section{Sensitization and provocation procedures}

Mice in asthma group were injected intraperitoneally with 100 ug ovalbumin (OVA) in $1 \mathrm{mg}$ aluminum hydroxide (Sigma) in a total volume of $0.25 \mathrm{ml}$ of PBS twice at day 1 and 8 , and then challenged with OVA aerosols (1\% in PBS) for 30 min per day for 7 consecutive days. The control mice were sensitized and challenged with PBS instead. For the glucocorticoid-treated group, mice were inhaled budesonide suspension (0.5 mg/per mouse; R\&D) $30 \mathrm{~min}$ before each challenged [6].

\section{Airway responsiveness analysis}

Expiratory resistance (Re) measurements of airway hyperresponsiveness (AHR) were made basally and in response to increasing doses of methacholine (Sigma-Aldrich). Methacholine was given over $5 \mathrm{~min}$ and the average Re value was measured $5 \mathrm{~min}$ after treatment.

\section{Bronchoalveolar Lavage (BAL) and serum collected}

We anesthetized the mice by an intraperitoneal injection of chloral

*Corresponding author: Cai-qing Zhang, Department of Pulmonary Disease, Qianfoshan Hospital, Shandong University, NO.16766 by the 10 Run Road, Jinan, Shandong, 250014, China, E-mail: freezcq66@163.com

Liang Dong, Department of Pulmonary Diseases, Qilu Hospital of Shandong University, NO.44,Wenhua Xi Road, Jinan, Shandong, 250012, China, E-mail: d15506@aliyun.com

Received July 27, 2013; Accepted September 15, 2013; Published September 20, 2013

Citation: Li HJ, Liu F, Lu DG, Song YH, Wang C, et al. (2013) IL-25 Involved in Airway Inflammation of OVA-Induced Asthmatic Mice and the Inhibitory Effect of Glucocorticoid. J Allergy Ther 4: 151. doi:10.4172/2155-6121.1000151

Copyright: (c $2013 \mathrm{Li} \mathrm{HJ}$, et al. This is an open-access article distributed under the terms of the Creative Commons Attribution License, which permits unrestricted use, distribution, and reproduction in any medium, provided the original author and source are credited. 
Citation: Li HJ, Liu F, Lu DG, Song YH, Wang C, et al. (2013) IL-25 Involved in Airway Inflammation of OVA-Induced Asthmatic Mice and the Inhibitory Effect of Glucocorticoid. J Allergy Ther 4: 151. doi:10.4172/2155-6121.1000151

Page 2 of 5

hydrate ( $4 \mathrm{mg} / \mathrm{g}$ body weight) at 24 hours after the last challenge. Blood was collected by cardiac puncture and serum was stored at $-70^{\circ} \mathrm{C}$ after centrifugation [7]. Brocho-alveolar lavage (BAL) was performed with PBS lavage six times $(0.5 \mathrm{ml}$ each time) through the cannulated trachea. A total of $2.5 \mathrm{ml}$ BAL fluid was collected from every mouse [8]. The supernatant was decanted and stored at $-80^{\circ} \mathrm{C}$ for further analysis.

\section{Histology}

Lungs tissues were excised completely from the chest cavity, and fixed with $10 \%$ neutral buffered formalin and then stained with hematoxylin and eosin (H\&E) [9]. All images were developed at $\times 40$.

\section{Inflammatory cells count}

We examined the cellular influx in the BALF by cell counting plate. The cell pellet was resuspended with PBS and washed twice and was subjected to count the number of eosinophils with Wright's staining. All scoring and measurements were performed blinded by the same observer. Two hundred leukocytes were counted in each slide. Differential counts of cells were performed at $\times 400$ (dry objective) using an Olympus microscope (Olympus). Cell types were identified based on morphologic criteria.

\section{Cytokines in BALF and IgE in serum by ELISA}

The levels of immunoglobulin (IgE) in serum and IL-25、IL-4 、IL-5、IL-13 and interferon (IFN)- $\gamma$ in the BAL supernatants were examined accordingly by ELISA kits (R\&D Systems) as described in the instructions. The kit is a solid phase phase sandwich enzyme linked immuno sorbent assay (ELISA). Samples were first pipetted into the wells. During the first incubation, the antigen and a biotinylated monoclonal antibody are simultaneously incubated. After washing, the enzyme (streptavidin-peroxydase) is added. After incubation and washing to remove the unbound enzyme, a substrate solution which is acting on the bound enzyme is added to induce a colored reaction product. The intensity of this colored product is directly proportional to the concentration of inflammatory cytokines present in the samples.

\section{Quantitative real-time PCR}

Total RNA was isolated from mouse bronchus by the RNeasy Mini Kit (Qiagen, West Sussex, United Kingdom) and then reverse transcribed with random hexamers and AMV reverse transcriptase (Promega, Southampton, United Kingdom). cDNA was amplified by SYBR Green PCR Master Mix Reagent (Qiagen) in Rotor Gene 3000 (Corbett Research, Sydney, Australia). PCR conditions were $95^{\circ} \mathrm{C} 10 \mathrm{~s}$, then 35 cycles of $95^{\circ} \mathrm{C} 5 \mathrm{~s}, 56^{\circ} \mathrm{C} 10 \mathrm{~s}, 72^{\circ} \mathrm{C} 10 \mathrm{~s}$. The quantity of IL-25 expression was assessed by the comparative $\mathrm{Ct}$ method. Glyceraldehyde 3-phosphate dehydrogenase (GAPDH) was used as a loading control.

\section{Immunohistochemistry analysis}

The sections were dewaxed, rehydrated and antigen retrieval was performed with $10 \mathrm{mM}$ sodium citrate ( $\mathrm{pH}$ 6.1). The slides were incubated with an anti-IL-25 antibody (Santa Cruz, USA) (1:25) overnight at $4^{\circ} \mathrm{C}$ and then processed with polyclonal rabbit anti-goat immunoglobulins/horseradish peroxidase (HRP) (1:100) for $30 \mathrm{~min}$ at $37^{\circ} \mathrm{C}$. The nuclei were counterstained with hematoxylin. Control slides were incubated with normal Ig instead of a primary anti-body. IL-25positive areas were quantified by densitometry using the image-pro plus software (Media Cybernetics, USA).

\section{Statistical analysis}

All the data were analyzed and computed by SPSS17.0 and demonstrated as mean \pm standard deviation (SD). Both the level of cytokines and the quantity of IL-25 were analyzed by one-way analysis of variance. Person correlation analysis was performed to test the linear relationship between the quantitative variables. All test results were considered significant at $p<0.05$.

\section{Results}

\section{Asthmatic model}

This model was confirmed by detecting airway responsiveness, airway inflammation, serum levels of IgE and lung histopathology. As shown in Figure 1, the expiratory resistance of OVA-group mice was elevated, which indicated the marked airway hyperresponsiveness. The serum levels of IgE were increased dramatically in OVA-challenged mice relative to values in control group (Table 1). Histological analysis demonstrated an asthmatic phenotype with significantly increased airway eosinophil infiltration and goblet cell metaplasia (Figure 2). All these data indicate that we successfully generated the asthma mouse model by OVA.

\section{Inflammatory cells}

To determine the inflammatory response of mice, we examined

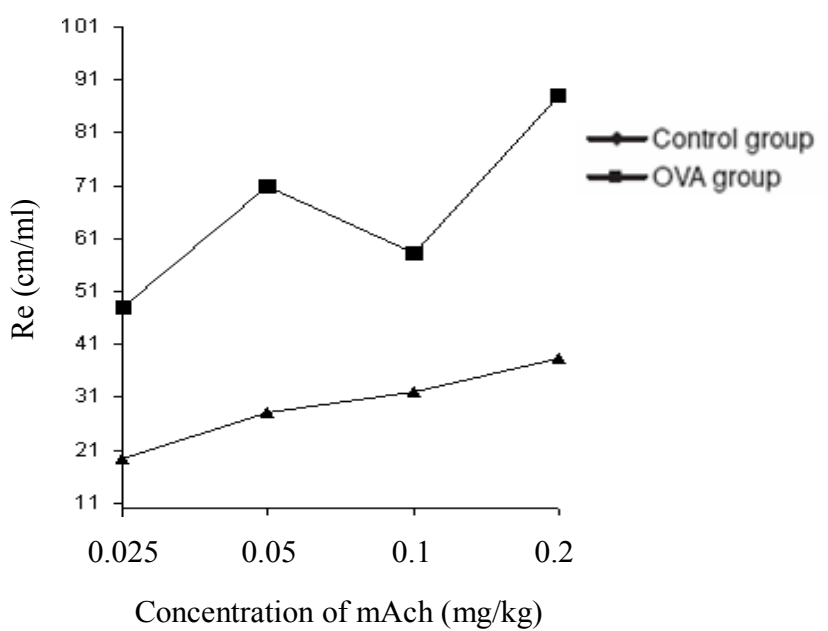

Figure 1: Airway responsiveness in mice. Expiratory resistance was measured to assess airway responsiveness. Expiratory resistance was detectable in OVA model and in a methacholine dose-dependent manner.

\begin{tabular}{|l|c|c|}
\hline Group N & Total lgE (ng/ml) & OVA-lgE (EU/ml) \\
\hline Asthma 10 & $216 \pm 31^{\mathrm{a}}$ & $44 \pm 5^{\mathrm{a}}$ \\
\hline Control 10 & $29 \pm 3$ & $<10$ \\
\hline
\end{tabular}

alndicates a p-value of less than 0.05 , compared with control group Table 1: Concentration of total and OVA-specific IgE in serum.

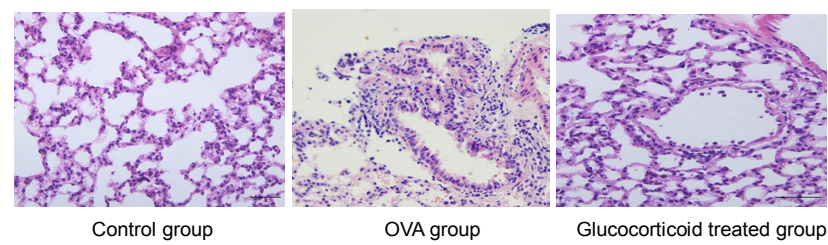

Figure 2: Lung histology. Sections of lung tissues were harvested 24 hours after last challenge, fixed with buffered formalin, and $5-\mu \mathrm{m}$ sections were analyzed by $\mathrm{HE}$ staining. Original magnification, $\times 40$. 


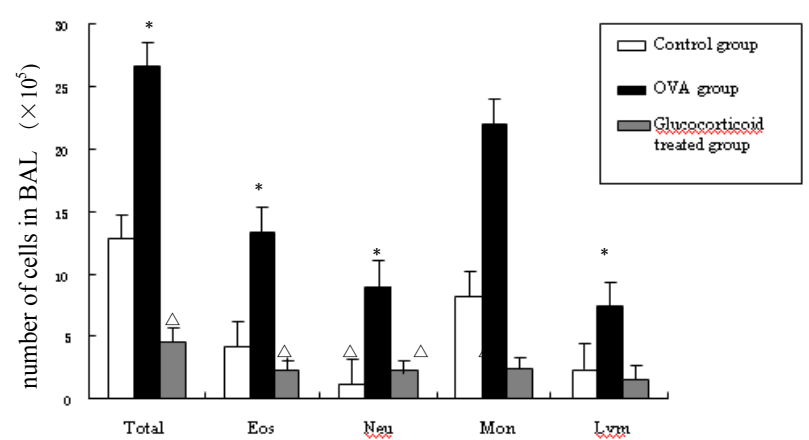

Figure 3: Quantify the number of cells in BALF. Values of cells represent the mean \pm SD. $* p<0.05$ compared with control group, ${ }^{\Delta} p<0.05$ compared with OVA group.

\begin{tabular}{|l|l|l|l|l|l|l|}
\hline Group & N & IFN-y & IL-4 & IL-5 & IL-13 & IL-25 \\
\hline OVA & 10 & $27.58 \pm 3.40^{\mathrm{a}}$ & $58.11 \pm 8.09^{\mathrm{a}}$ & $97.41 \pm 11.04^{\mathrm{a}}$ & $81.73 \pm 8.25^{\mathrm{a}}$ & $189.67 \pm 18.15^{\mathrm{a}}$ \\
\hline Control & 10 & $70.96 \pm 2.08$ & $20.30 \pm 1.88$ & $28.17 \pm 4.11$ & $26.53 \pm 1.09$ & $70.96 \pm 14.31$ \\
\hline GC & 10 & $64.97 \pm 4.51^{\mathrm{b}}$ & $32.18 \pm 6.12^{\mathrm{b}}$ & $19.45 \pm 2.03^{\mathrm{b}}$ & $21.82 \pm 3.51$ & $76.39 \pm 9.58^{\mathrm{b}}$ \\
\hline F-value & & 116.12 & 231.04 & 85.04 & 79.87 & 103.08 \\
\hline P-value & $<0.01$ & $<0.01$ & $<0.01$ & $<0.01$ & $<0.01$ \\
\hline
\end{tabular}

alndicates a $p$-value of less than 0.05 , compared with control group 'Indicates a $p$-value of less than 0.05 , compared with OVA group

Table 2: The expression of IL-25, IL-4, IL-5, IL-13 and IFN-y in BALF by ELISA $(\bar{x} \pm \mathrm{s}, \mathrm{pg} / \mathrm{ml})$.

\begin{tabular}{|l|l|l|l|l|}
\hline Group & $\mathbf{N}$ & $\begin{array}{l}\text { GAPDH }-\mathbf{C t} \\
\text { (Ct-G) }\end{array}$ & $\begin{array}{l}\text { IL-25-Ct } \\
(\mathbf{C t}-\mathbf{2 5})\end{array}$ & $\mathbf{2}^{\Delta \Delta \mathbf{C t}}$ \\
\hline OVA & 10 & $15.79 \pm 0.81$ & $16.03 \pm 5.87^{\mathrm{a}}$ & $1.48 \pm 0.07^{\mathrm{a}}$ \\
\hline Control & 10 & $14.02 \pm 0.57$ & $29.65 \pm 0.74$ & $0.74 \pm 0.03$ \\
\hline GC & 10 & $14.21 \pm 0.69$ & $27.48 \pm 1.28^{\mathrm{b}}$ & $0.81 \pm 0.06^{\mathrm{b}}$ \\
\hline F-value & & 42.75 & 59.82 & 105.34 \\
\hline P-value & & $<0.01$ & $<0.01$ & $<0.01$ \\
\hline
\end{tabular}

alndicates a $p$-value of less than 0.05 , compared with control group ${ }^{b}$ Indicates a $p$-value of less than 0.05 , compared with OVA group

Table 3: Quantitative detection of IL-25 mRNA in airway epithelium ( $\bar{x} \pm s)$.

the cellular influx in the BALF by cell counting plate (Figure 3). The number of total BALF cells was much higher in OVA group than in the control group. Mice exposed to OVA also demonstrated a significant increase in the number of eosinophils, neutrophils, lymphocytes and macrophages.

\section{Inflammatory cytokines}

In the supernatants of BALF, we also detected much higher secretion of IL-4、IL-5, IL-13 as well as IL-25 with lower level of IFN- $\gamma$ than the control group (Table 2). These results indicate that IL-25 worked in synergy with other Th2-type cytokines such as IL-4, IL-5 and IL13 to induce the recruitment of eosinophils in OVA induced asthmatic airway and thus promoted the Th2-type inflammatory responses in asthmatic airway inflammation.

\section{IL-25 Expression in asthmatic mice}

To identify the role of IL-25 in OVA-induced asthmatic mice, we detected the expression of IL-25 mRNA by quantitative real-time PCR and IL-25 protein by immunohistochemistry, respectively. The expression of IL-25 mRNA and protein on tracheal of mice exposed to OVA were significantly higher than that of mice in control group
(Tables 3 and 4) (Figure 4). Tight Connection between the Expression of IL-25 and the Up-regulation of Cytokines

To clarify the role of IL-25 on Th2-type cytokines, we performed a Person correlation analysis between IL-25 mRNA and IL-4, IL-5, IL-13 and IFN- $\gamma$ in BALF. All the quantitative variables were showed normal distribution and we tested the linear relationship between IL-25 and the every other quantitative variable with Person correlation analysis. We found the expression of IL-25 mRNA was tightly positive correlated with the levels of IL-4 ( $r=0.748)$, IL-5 $(r=0.691)$, and IL-13 ( $r=0.793)$ and negative correlated with the levels of IFN- $\gamma(\mathrm{r}=-0.574)$ (Figure 5). Thus Th2-type inflammation played a pivotal role in maintaining and sustaining asthmatic inflammation, and we presumed that IL-25 could activate eosinophils to produce such a range of asthmatic mediators and triggered the activation of Th2-type related cytokines network.

\section{Glucocorticoid inhibited cells infiltration and reduced cytokines level}

We used inhaled budesonide during the challenge phase to determine the effect of glucocorticoid in the pathology of asthma. Inhaled budesonide resulted in the decrease of IL-25 mRNA in allergic mice; mice treated with inhaled budesonide showed a reduction in eosinophils infiltration in airway (Figure 2) as well as the levels of IL-25, IL-4, IL-5, and IL-13 in BALF (Figure 6). However there is no difference between the glucocorticoid treated group and the control group.

\section{Discussion}

IL-25 was identified as being necessary for the up-regulation of the

\begin{tabular}{|l|l|l|}
\hline Target & GAPDH (131bp) & IL-25 (192bp) \\
\hline Forward & 5'-AACAGGCGTCCCTTTCCGA-3' & 5'-CAGCAAAGAGCAAGAACC-3' \\
\hline Reverse & 5'- GCCCAAGATGCCCTTCAGT-3' & 5'-CCCTGTCCAACTCATAGC-3' \\
\hline
\end{tabular}

Table 4: Primers of GAPDH and IL-25 used in study.

$\mathbf{A}$
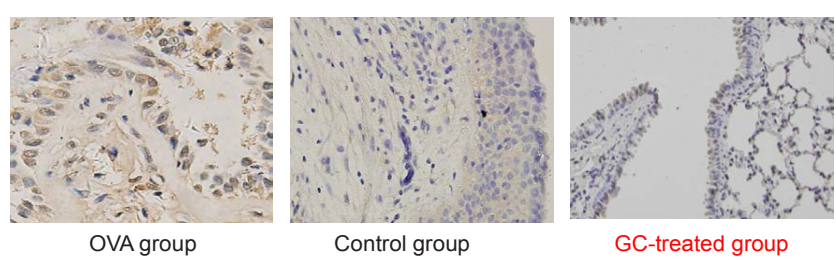

B

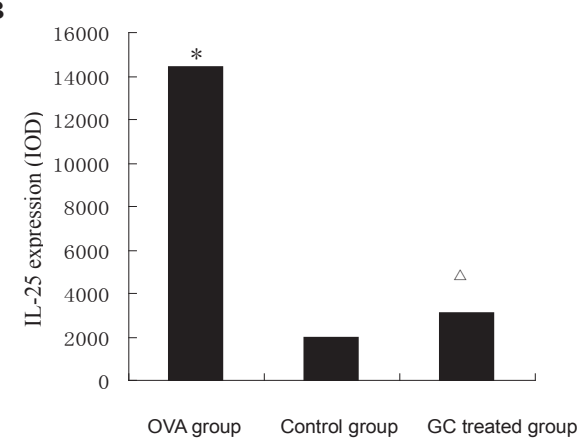

Figure 4: Expression of IL-25 in lungs. (A) IL-25 staining is up-regulated in airway epithelial cells and the inflammatory cells around the larger airways and blood vessels in asthma group while the control and the gucocorticoid (GC) treated group showed less staining. (B) Quantitation of IL-25. $* p<0.05$ compared with control group, ${ }^{\Delta} p<0.05$ compared with OVA group. 

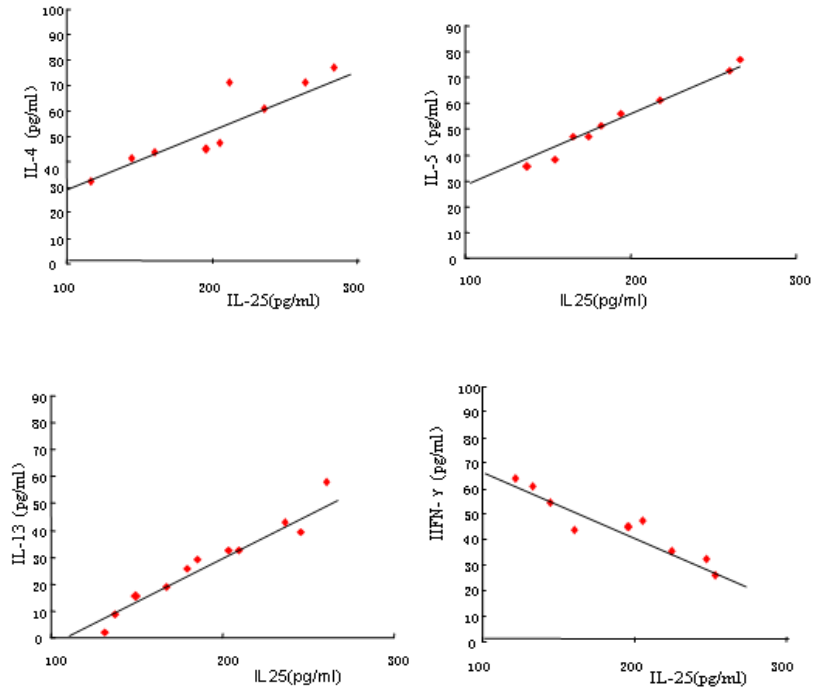

Figure 5: Tight connection between the expression of IL-25 and IL-4, IL-5, $\mathrm{IL}-13$ and IFN- $Y$ in BALF. $\left(r_{\mathrm{IL}-4}=0.748, r_{\mathrm{IL}-5}=0.691, r_{\mathrm{IL}-13}=0.793, r_{\mathrm{IFN}-\mathrm{Y}}=-0.574\right.$, $p<0.05)$.

$\mathbf{A}$

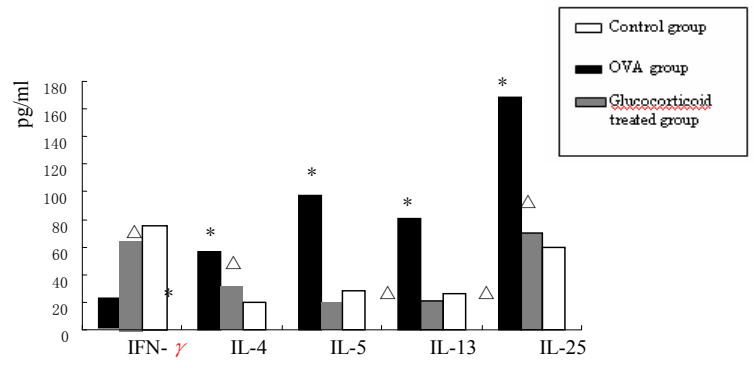

B

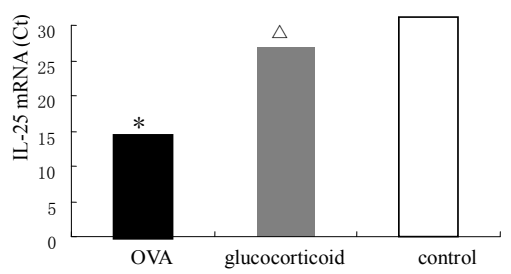

Figure 6: The effect of glucocorticoid treatment. (A) The levels of IL-25, IL-4, IL-5, IL-13 and IFN- $y$ in BALF; (B) IL-25 mRNA of lungs. $* p<0.05$ compared with control group, ${ }^{\wedge} p<0.05$ compared with OVA group.

Th2 effecter cytokines and mirroring the role of Th1 response, such as asthma [1]. In this study, we showed that the expression of IL-25 was tightly positive correlated with the levels of IL-4, IL-5 and IL-13 and negative correlated with the levels of IFN- $\gamma$, which demonstrated that IL-25 was emerging as a key regulator of asthmatic inflammation because of its ability to promote Th2, while suppress Th1 cytokine responses. While $\mathrm{T}$ lymphocytes are responsible for driving allergenspecific type 2 responses, multiple reports have identified critical roles for innate immune responses. First, IL-25 could activate CD4+ T cells to produce chemokines and exacerbate asthmatic inflammation. Besides, IL-25 could induce eosinophils, IL-4, IL-5 secretion and lead to airway hyperresponsiveness and inflammatory response. Therefore, IL-25 acted as the bridge between the innate and the adaptive immune responses in allergic asthma needs our further investigation [2]. Besides, there are also controversial reports regarding the cell types that produce IL-25. For example, Fort et al. [10] showed that IL-25 was expressed exclusively by Th2 cells, whereas Wang et al. [4] demonstrated that eosinophils and basophils, but not other immune cells (T cells, B cells, monocytes, dendritic cells, etc.), secreted IL-25. Our immunohistochemistry analysis showed that IL-25 was highly expressed in epithelial cells of the airway in mice with asthma, which was consistent with the research of Klein et al. [11]. We also demonstrated that in the lungs of mice with asthma, the expression of IL-25mRNA and protein is increased in the airway epithelium. These results confirm that IL-25 is markedly over expressed in the lungs of mice sensitized and challenged with OVA $[10,12]$.

Glucocorticoid treatment had long been considered to be the way to decrease asthmatic inflammation [13]. When the asthmatic animals were given inhaled budesonide treatment, this airway inflammation could also be inhibited by the decrease of inflammatory cells and cytokines infiltration [14]. In our study, animals receiving budesonide inhalation showed a significant decrease in total and classified cells as well as Th2 cytokines levels (IL-4, IL-5, and IL-13) in BALF. Although our data supported IL-25 acting with other Th2 cytokines in asthmatic inflammation, mice deficient in IL-4, IL-5, and IL-13 could also induced AHR with IL-25 administration, which showed independently of the classic Th2 inflammatory reposes. Besides, current clinical studies have found that some asthmatic patients were resistant to glucocorticoid treatment even with high dose and the animal studies also showed that steroid resistant Th17 cells might explain neutrophilmediated asthmatic inflammation [15]. Since IL-25 is one of the IL17 family members, IL-25 signaling pathway might provide a novel target for steroid-resistant asthmatic therapy, which needs our further research into mechanisms underlying asthma's pathophysiology [16]. Further investigation will also be required to determine whether IL25 acts through the induction of known broncho-constrictors such as the leukotrienes, or via molecules such as the recently described acidic chitinase [17].

\section{Conclusion}

The expression of IL-25 was increased in airway of asthma as well as other Th2-related cytokines secretion [18]; while budesonide inhalation could reduce type 2 cytokine induced inflammation and prevent airway hyperresponsiveness [19]. It is noteworthy that IL-25 might provide a novel target in the glucocorticoid therapeutic intervention of asthmatic inflammation.

\section{Acknowledgement}

The authors gratefully thank Dr. Rutao Cui for supplying IL-25 antibody. This work was finished in Key Laboratory of Cardiovascular Remodeling and Function Research of Chinese Ministry of Education and Public Health, Shandong University Qilu Hospital and medical research center of Shandong University Qianfoshan Hospital. This work was supported by the Natural and Science Foundation of Shandong Province (ZR2011HM020), The National Natural Science Foundation of China (81270072) and The Science and Technology Foundation of Shandong Province (2012GGB14068).

\section{References}

1. Antus B (2012) [Clinical application of induced and spontaneous sputum in asthma and chronic obstructive pulmonary disease]. Orv Hetil 153: 1847-1854.

2. Yang Z, Grinchuk V, Urban JF Jr, Bohl J, Sun R, et al. (2013) Macrophages as IL-25/IL-33-responsive cells play an important role in the induction of type 2 immunity. PLoS One 8: e59441.

3. Kim JY, Jeong MS, Park KY, Seo SJ (2013) Aggravation of atopic dermatitis-like 
Citation: Li HJ, Liu F, Lu DG, Song YH, Wang C, et al. (2013) IL-25 Involved in Airway Inflammation of OVA-Induced Asthmatic Mice and the Inhibitory Effect of Glucocorticoid. J Allergy Ther 4: 151. doi:10.4172/2155-6121.1000151

Page 5 of 5

symptoms by consecutive low concentration of formaldehyde exposure in $\mathrm{NC} /$ Nga mice. Exp Dermatol 22: 219-221.

4. Wang YH, Angkasekwinai P, Lu N, Voo KS, Arima K, et al. (2007) IL-25 augments type 2 immune responses by enhancing the expansion and functions of TSLP-DC-activated Th2 memory cells. J Exp Med 204: 1837-1847.

5. Silverman J, Baker SP, Lidz CW (2012) A self-assessment survey of the Institutional Animal Care and Use Committee, Part 1: animal welfare and protocol compliance. Lab Anim (NY) 41: 230-235.

6. Marwick JA, Stevenson CS, Chung KF, Adcock IM, Kirkham PA (2010) Cigarette Smoke Exposure Alters mSin3a and Mi-2alpha/beta Expression; implications in the control of pro-inflammatory gene transcription and glucocorticoid function. J Inflamm (Lond) 7: 33.

7. Chan YK, Davis PF, Poppitt SD, Sun X, Greenhill NS, et al. (2012) Influence of tail versus cardiac sampling on blood glucose and lipid profiles in mice. Lab Anim 46: 142-147.

8. Neill DR, Wong SH, Bellosi A, Flynn RJ, Daly M, et al. (2010) Nuocytes represent a new innate effector leukocyte that mediates type-2 immunity. Nature 464: 1367-1370.

9. Groves AM, Gow AJ, Massa CB, Laskin JD, Laskin DL (2012) Prolonged injury and altered lung function after ozone inhalation in mice with chronic lung inflammation. Am J Respir Cell Mol Biol 47: 776-783.

10. Fort MM, Cheung J, Yen D, Li J, Zurawski SM, et al. (2001) IL-25 induces IL-4, IL-5, and IL-13 and Th2-associated pathologies in vivo. Immunity 15: 985-995.

11. Klein Wolterink RG, Hendriks RW (2013) Type 2 innate lymphocytes in allergic airway inflammation. Curr Allergy Asthma Rep 13: 271-280.
12. Kaiko GE, Foster PS (2011) New insights into the generation of Th2 immunity and potential therapeutic targets for the treatment of asthma. Curr Opin Allergy Clin Immunol 11: 39-45.

13. Stock P, Lombardi V, Kohlrautz V, Akbari O (2009) Induction of airway hyperreactivity by IL-25 is dependent on a subset of invariant NKT cells expressing IL-17RB. J Immunol 182: 5116-5122.

14. Barlow JL, Flynn RJ, Ballantyne SJ, McKenzie AN (2011) Reciprocal expression of IL-25 and IL-17A is important for allergic airways hyperreactivity. Clin Exp Allergy 41: 1447-1455.

15. Ano S, Morishima Y, Ishii Y, Yoh K, Yageta Y, et al. (2013) Transcription factors GATA-3 and RORyt are important for determining the phenotype of allergic airway inflammation in a murine model of asthma. J Immunol 190: 1056-1065.

16. Petersen BC, Budelsky AL, Baptist AP, Schaller MA Lukacs NW (2012) Interleukin-25 induces type 2 cytokine production in a steroid-resistant interleukin-17RB+ myeloid population that exacerbates asthmatic pathology. Nat Med 18: 751-758.

17. Rickel EA, Siegel LA, Yoon BR, Rottman JB, Kugler DG, et al. (2008) Identification of functional roles for both IL-17RB and IL-17RA in mediating IL25-induced activities. J Immunol 181: 4299-4310.

18. Saenz SA, Siracusa MC, Perrigoue JG, Spencer SP, Urban JF Jr, et al. (2010) IL25 elicits a multipotent progenitor cell population that promotes $\mathrm{T}(\mathrm{H}) 2$ cytokine responses. Nature 464: 1362-1366.

19. Gregory LG, Jones CP, Walker SA, Sawant D, Gowers KH, et al. (2013) IL25 drives remodelling in allergic airways disease induced by house dust mite. Thorax 68: 82-90.

This article was originally published in a special issue, Airway

Inflammation

and Hyperresponsiveness handled by Editor. Dr. John F Alcorn,

Children's

Hospital of Pittsburgh, USA 